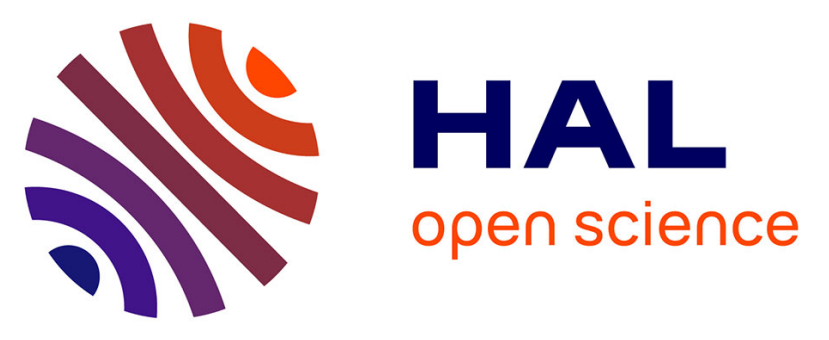

\title{
Meta-omics Provides Insights into the Impact of Hydrocarbon Contamination on Microbial Mat Functioning
}

Johanne Aubé, Pavel Senin, Patricia Bonin, Olivier Pringault, Céline Jeziorski, Olivier Bouchez, Christophe C. Klopp, Remy Guyoneaud, Marisol Goñi

\section{To cite this version:}

Johanne Aubé, Pavel Senin, Patricia Bonin, Olivier Pringault, Céline Jeziorski, et al.. Meta-omics Provides Insights into the Impact of Hydrocarbon Contamination on Microbial Mat Functioning. Microbial ecology, 2020, 80 (2), pp.286-295. 10.1007/s00248-020-01493-x . hal-03065790

\author{
HAL Id: hal-03065790 \\ https://hal.science/hal-03065790
}

Submitted on 14 Dec 2020

HAL is a multi-disciplinary open access archive for the deposit and dissemination of scientific research documents, whether they are published or not. The documents may come from teaching and research institutions in France or abroad, or from public or private research centers.
L'archive ouverte pluridisciplinaire $\mathbf{H A L}$, est destinée au dépôt et à la diffusion de documents scientifiques de niveau recherche, publiés ou non, émanant des établissements d'enseignement et de recherche français ou étrangers, des laboratoires publics ou privés. 
1 Meta-omics provides insights into the impact of hydrocarbon contamination on microbial mats functioning

\section{Johanne Aubéa ${ }^{*}$, Pavel Senin ${ }^{a, b}$, Patricia Bonin ${ }^{c}$, Olivier Pringault ${ }^{\mathrm{d}}$, Céline Jeziorski ${ }^{\mathrm{e}}$,} Olivier Bouchez ${ }^{\mathrm{e}}$, Christophe Klopp ${ }^{\mathrm{b}}$, Rémy Guyoneaud ${ }^{\mathrm{a}}$, Marisol Goñi-Urriza $\#$

${ }^{\text {a }}$ Universite de Pau et des Pays de l'Adour, E2S UPPA, CNRS, IPREM, Environmental Microbiology, Pau, France

b Plateforme bioinformatique Genotoul, UR875 Biométrie et Intelligence Artificielle, INRA, Castanet-Tolosan, France

${ }^{\mathrm{c}}$ Aix Marseille Univ, Université de Toulon, CNRS/INSU/IRD, Mediterranean Institute of Oceanography (MIO), UM 110, Marseille, France

d UMR 9190 MARBEC IRD-Ifremer-CNRS, Université de Montpellier, Place Eugène Bataillon, Montpellier, France

${ }^{\text {e }}$ GeT-PlaGe, Genotoul, INRA Auzeville, Castanet-Tolosan, France

Keywords: microbial mats, metabolism, metagenomics, metatranscriptomic, functioning, diversity

\section{\# Address correspondence to Marisol Goñi-Urriza, marisol.goni@univ-pau.fr}

ORCID ID: 0000-0001-7694-6511

Present address

* IFREMER, CNRS, Université de Bretagne Occidentale, Laboratoire de Microbiologie des Environnements Extrêmes - UMR6197, Plouzané, France. 
Abstract

Photosynthetic microbial mats are stable, self-supported communities. Due to their

27 coastal localization, these mats are frequently exposed to hydrocarbon contamination and are able to grow on it. To decipher how this contamination disturbs the functioning of microbial mats, we compared two mats: a contaminated mat exposed to chronic petroleum contamination and a reference mat. The taxonomic and metabolic structures of the mats in spring and fall were determined using metagenomic and metatranscriptomic approaches. Extremely high contamination disturbed the seasonal variations of the mat. $\mathrm{ABC}$ transporters, two-component systems and type IV secretion systems related genes were overabundant in the contaminated mats. Xenobiotic degradation metabolism was minor in the metagenomes of both mats and only the expression of genes involved in Polyciclic Aromatic hydrocarbon degradation was higher in the contaminated mat. Interestingly, the expression rates of genes involved in hydrocarbon activation decreased during the 1-year study period, concomitant with the decrease in easily degradable hydrocarbons, suggesting a transient effect of hydrocarbon contamination. Alteromonadales and Oceanospirillales hydrocarbonoclastic bacteria appeared to be key in hydrocarbon remediation in the contaminated mat. Overall, the contaminated microbial mat was able to cope with hydrocarbon contamination and displayed an adaptive functioning that modified seasonal behaviour. 


\section{Introduction}

Photosynthetic microbial mats growing in coastal areas are among the most diverse and complex marine ecosystems [1]. The overall metabolism of a microbial mat is driven by solar light as the main energy source. Microbial activities generate physical and chemical gradients in the mat that maintain the structure and activity of the mat's community [2], leading to a stable, self-supported mat. Microbial mats are highly dynamic and are subjected to strong fluctuations at the diel or seasonal scales [2]. The extensive genetic and metabolic diversity of photosynthetic microbial mat-inhabiting organisms enable development in a wide variety of environments, including hot springs, hypersaline and alkaline environments and polar ponds $[1,3-6]$. Due to their localization in coastal zones, microbial mats are frequently subjected to hydrocarbon contamination $[7,8]$. The response of microbial mats to petroleum contamination has been studied in microcosm experiments and under natural conditions after acute pollution events (accidental or laboratory experiments). Microbial mats can cope with contamination and develop a robust community adapted to petroleum levels $[8,9]$. The few studies that have focused on chronic oil pollution have concluded that the structure of microbial mats is related to the level of contamination [8] and that contaminated mats can degrade hydrocarbons $[10,12]$. Generally, noticeable changes in composition $[8,10]$ of high contaminated mats are reported, and some studies described lower diversity in higher contaminated mats [13], but not overabundance of hydrocarbonoclastic microorganisms have been observed. Nevertheless, when these contaminated mats were submitted to fresh oil pollutions, an immediate induction of RHD genes involved in polyaromatic hydrocarbon degradation was observed, accompanied with an efficient degradation of crude oil [10]. This metabolic response (associated with a community structural shift [12]) was however quickly reversed, highlighting a fast, adaptive and efficient response of the metabolically active bacterial population. Oil contamination also impacts typical seasonal behaviour of 
photosynthetic microbial mats, by strongly inhibiting primary production and respiration in spring, but with no significant impact in fall [20]. As consequences, the typical overabundance of Cyanobacteria in fall compared to spring could not be observed in the higher contaminated mat [19]. These studies were performed using taxonomic and/or metabolic gene markers, such as ribosomal genes or genes involved in hydrocarbon degradation [9-14].

High-throughput sequencing of metagenomes and metatranscriptomes has provided an unprecedented overview of the functional capacities and gene expression of microbial communities confronting environmental stresses. As the presence and expression of genes involved in hydrocarbon degradation (including complete metabolic pathways) have been observed in oil spill-contaminated seawaters [15-17] and soils [18, 19], applying these sequencing techniques to contaminated microbial mats will provide new insights on the adaptation of microbial mats to hydrocarbon contamination.

The aim of this paper was to elucidate the impact of long-term petroleum contamination on the functioning of microbial mats. Two photosynthetic microbial mats located in the Berre lagoon, a brackish lagoon bordering the Mediterranean Sea in the South of France, were investigated in this work. These mats feature similar physical and chemical parameters (salinity, temperature, solar irradiation, etc.) [20] but have been subjected to differing hydrocarbon contamination levels. Specifically, the contaminated mat received hydrocarbon inputs from a petrochemical industry site for more than 80 years. By applying metagenome and enriched mRNA metatranscriptome sequencing, we described the key metabolic pathways of both microbial mats. Comparing the contaminated mat with the reference mat revealed the role of petroleum pollution in microbial community functioning. A deeper analysis of metabolism related to hydrocarbon-degradation pathways was also performed. 


\section{Sampling sites and procedure}

Berre lagoon is located on the Mediterranean French coast. Microbial mat samples were collected from two sites in the lagoon: a reference station located in the bird reserve “Les salins du Lion" (SL) (43.452570 N 5.230085 E) and a contaminated station located in a retention basin receiving hydrocarbon-contaminated rainfall water from a petrochemical industry site (EDB1) (43.484946 N 5.188452 E) [8, 21]. At this latter site, the hydrocarbon content reaches $96 \mu \mathrm{g} / \mathrm{g}$ [8]. In addition to this chronic contamination, an accidental oil spill occurred in September 2009 due to the overflow of a hydrocarbon-polluted water retention pond [22], which increased the hydrocarbon content. Three sampling exercises were performed: one in spring (April 2012) and two in fall (September 2011 and 2012), which were named Apr12, Sept11 and Sept12, respectively. A piece of mats (around $1.5 \mathrm{~m}^{2}$ ), including the top two centimetres of sediment were collected at mid-day as described in [19].

Subsamples for molecular analyses were stored at $-80^{\circ} \mathrm{C}$. A description of main physicalchemical characteristics and hydrocarbon composition of both sites can be found at Table S1.

Whole meta-genome and meta-transcriptome sequencing and bioinformatics procedures DNA and RNA were co-extracted in triplicate using an RNA PowerSoil Total RNA Isolation Kit (MO BIO Laboratories, Inc.) coupled with an AllPrep DNA/RNA Mini Kit (QIAGEN) for DNA and RNA separation. RNA was digested with an RNase-Free DNase Set (QIAGEN) for DNA removal, and RNA quality was checked as described by Aubé and coworkers [20]. Genomic DNA libraries were constructed using a NEXTflex PCR-free DNA Sequencing Kit from BioScientific PCR-free kit following the manufacturer's protocol. RNAseq libraries were prepared according to Illumina's protocol on a Tecan EVO200 liquid handler. An Illumina TruSeq Stranded mRNA sample prep kit was used to analyse RNA after 
mRNA enrichment using an Epicentre Ribo-Zero rRNA removal kit. RNA was fragmented to generate double-stranded cDNA. Ten cycles of PCR were used to amplify libraries following manufacturer's instructions (Illumina TruSeq Stranded mRNA library prep kit, Cat. No. RS122-2101), and the libraries were precisely quantified by qPCR using a KAPA Library Quantification Kit. RNA-seq and gDNA sequencing were performed with an Illumina HiSeq2500 instrument using a paired-end read length of $2 \times 100 \mathrm{bp}$ with an Illumina TruSeq SBS sequencing kit v3.

The Trim Galore! utility was used for read quality control http://www.bioinformatics.babraham.ac.uk/projects/trim_galore/). Possible adapter sequences based on the Illumina TruSeq Adapter index were removed from the reads. Data filtering was performed with cutadapt [23] and FASTX-Toolkit

(http://hannonlab.cshl.edu/fastx_toolkit/index.html) by trimming reads with a Q score of less than 15 at the 3 ' end, trimming unidentified $\mathrm{dNTP}(\mathrm{N})$ at the read ends and discarding reads with Ns $>10 \%$. Reads shorter than 50 bp with low-quality bases $(\mathrm{Q}<20)$ were also discarded. For functional and taxonomic annotations, all filtered reads (DNA and mRNA) were aligned to the KEGG gene database [24] using LAST aligner v392 [25]. Each read was then annotated using the single-directional best hit information method [26] with an identity cut-off of $60 \%$ and a score of 96. Eukaryotic sequences were removed from the dataset. Statistics of the reads at each bioinformatics analysis step are shown in the supplementary material (Table S2).

\section{Statistical analysis}

Before statistical analysis, random sampling of filtered data was performed to obtain the same number of reads per sample (i.e. the minimum number of sequences in metagenomic or metatranscriptomic samples (Table S2)) and the means of the pseudo-triplicates were calculated to perform statistical tests. Taxonomic biomarkers of hydrocarbon contamination were detected using the LEfSe algorithm [27]. The first analysis step was a non-parametric 
143 Kruskal-Wallis (KW) sum-rank test to detect taxa and functional pathways with significant

144 differential abundances. Biological consistency was subsequently investigated using a

145 pairwise Wilcoxon test. Finally, linear discriminant analysis (LDA) was used to estimate the

146 effect size of each differentially abundant taxon. Alpha values of 0.05 were used for the KW

147 and Wilcoxon tests, and a threshold of 2 was used for the logarithmic LDA scores. Gene and

148 transcript abundances for functional data were compared using a two-group White's non-

149 parametric t-test in STAMP [28] by KEGG subsystem. To account for the variation of

150 transcriptional activity, the gene expression rate was calculated as described by Stewart el al

151 [29]. Hydrocarbon content were analysed by principal component analysis (PCA) using the

152 FactoMineR package [30]; variables with $\cos 2$ below 0.5 on each factorial plane are not

153 shown on the corresponding correlation circles of the PCA.

154 Accession number

155

The sequence data are available in the Sequence Read Archive of the National Center

156 for Biotechnology Information under accession number SRP063590.

157 


\section{Results and discussion}

Microbial mats are highly stratified systems, in which microorganisms' metabolism supports their physical and chemical structure. In return, physical and chemical conditions of the mats favours microbial specific metabolisms: structure and function are thus slightly dependent. The goal of the present study was to determine if pollution changes metabolic profiles and its consequences on coastal mat's structure and functioning.

\section{Structure of microbial mat communities}

The metagenomes and metatranscriptomes of the microbial mats were annotated using the KEGG database. Between $24.70 \%$ and $46.86 \%$ of the metagenome and metatranscriptome sequences, respectively, aligned to the KEGG database (Table S2). The community composition based on the taxonomic affiliations of protein-encoding genes revealed a structure similar to that described by 16S rRNA gene affiliations [20] and to those of other mats [31, 32]; i.e. Proteobacteria, Cyanobacteria, and Bacteroidetes were dominant (Fig. 1) with metagenomes mean relative abundance of $48.1 \%, 16.0 \%$ and $15.5 \%$ respectively. The high similarity between the structure described here and those described in previous studies on the same mats based on $16 \mathrm{~S}$ rDNA sequences $[8,19]$, supported the robustness of the annotation approach. Oscillatoriales dominated among Cyanobacteria. The relative abundance of Cyanobacteria was highest in the EDB1 Sept12 metagenomes and metatranscriptomes, with a greater abundance of Rivulariaceae (Table S3). Among the Deltaproteobacteria ( $10.8 \%$ of the metagenomes mean relative abundance) most of the sequences were affiliated with sulphate reducers in the order Desulfobacterales (Table S3). The sequences related to Gammaproteobacteria $(15.0 \%$ of the metagenomes mean relative abundance) were affiliated with Alteromonadales and Chromatiales; most of the 
and $4.3 \%$ of the metagenomes mean relative abundance), Rhodobacterales and

Burkholderiales dominated, respectively. Consistent with observations in the Guerrero Negro hypersaline microbial mats and Highborne Cay mat (The Bahamas) [33, 34], Archaea were in the minority in the microbial communities, accounting for $1 \%$ to $3 \%$ of total reads and mainly represented by the methanogens Methanomicrobia. Thus, both mats are classical mats with dominance of photosynthetic bacteria and bacteria involved in the sulphur cycle (sulphate reducers and sulphur oxidizers [2]).

The community structures described using metatranscriptomic data differed from those described by metagenomic data (Fig. 1). Remarkably, transcripts related to Cyanobacteria highly dominated the communities in both mats, accounting for $36.5 \%$ to $78 \%$ of the reads, highlighting the major role of Cyanobacteria compared to other functional groups in the mats $[34,35]$.

As microbial mat functioning is dependent on the seasonal period [36], sampling was performed in spring and fall to assess the seasonal variation of the structure and activity of the mats. The reference mat showed typical seasonal variations characterized by 1) an increase of Cyanobacteria in fall (around 13\% of metagenomic data in spring and 19\% in fall, Table S3); and, 2) an increase of the sulphur related microorganisms in spring. This increase was observed either at metagenomic (from near $14 \%$ in fall to $19 \%$ in spring) or at metatranscriptomic level (a mean of $6 \%$ in fall and $21 \%$ in spring, Table S3) and mainly concerned Desulfobacterales and Chromatiales. On the contrary, no seasonal variations were observed in the contaminated mat: Cyanobacteria highly dominated the community in Sept12 but not in Sept11 samples, and a continuous decrease of the relative abundance of microorganisms related to sulphur cycle, either at metagenomics or metatranscriptomic level, was observed in the contaminated mat (Table S3). 
A total of 7,009 different KEGG ortholog groups (KOs) were detected in the metagenome, and 6,470 KOs were detected in the metatranscriptome. Among the annotated reads, around $44 \%$ of the microbial mat metagenomes matched genes involved in pathways associated with metabolism (Fig. 2); including 10.2-11.1\% related to genes involved in carbohydrate metabolism (547 KOs); and 9.9-10.8\% related to amino acid metabolism (420 KOs). Energy metabolism-related sequences represented only $4.1-4.5 \%$ of the metagenomes but up to $49.9 \%$ of the metatranscriptomes (389 and 381 KOs for genes and transcripts, respectively). Among them, photosynthesis metabolism-related genes (i.e. genes encoding proteins of photosystems I and II (P700 and P680) and phycobiliproteins (phycocyanin, allophycocyanin and phycoerythrin subunits)) exhibited maximum expression rates of 1094 .

Genes related to nitrogen and sulphur metabolism exhibited high expression rates as well. Sequences related to nitrogen metabolism were mainly involved in nitrogen fixation (i.e. nitrogenase enzyme complex); among them, nifH exhibited expression rates as high as 5.85. The sequences related to the sulphur cycle were involved in sulphate reduction: adenylylsulphate reductase and sulphite reductase (AprAB and DsrAB) exhibited maximum expression rates of 8.83 (data not shown).

While reference mat showed a typical seasonal behaviour, contaminated mat did not show the same behaviour. In this case, the comparison of metabolic potentials of both mats in order to define which of them are related to the contamination is challenging. For further analysis on hydrocarbon contamination impact on microbial mat functioning, all the samples for each mat (reference or contaminated) have been averaged. This approach could probably dissimulate some metabolisms, but eliminates the errors originating from a seasonal divergent functioning. 
Metabolic and taxonomic differences between sites with focus on metabolic pathways associated with xenobiotic degradation

Microbial communities from coastal environments impacted by punctual oil input have been intensively studied (e.g. $[16,37,38])$, and a decrease in microbial diversity associated with dominance of hydrocarbon-degrading marine bacteria is generally observed following an oil spill [39]. By contrast, in this study, dominance of hydrocarbonoclastic bacteria in the contaminated mat compared to the reference mat was not observed, consistent with previous studies of chronically contaminated sites $[8,40]$. At the taxonomic level, 36 and 3 differentially abundant taxa were detected based on metagenomic and metatranscriptomic data, respectively (Fig. 3). At the metagenomic level, the main difference was a decrease in the relative abundance of some phylogenetic groups (Fig. 3a), suggesting a sensitivity of those groups to contamination. At the transcriptomic level (Fig. 3b), few taxa appear characteristic of each mat. Only Parvularculales within Alphaproteobacteria, were characteristic taxa of the contaminated mat. Alphaproteobacteria are key contributors to the later stages of oil degradation [41]. However, hydrocarbon degradation is strain specific; phylogenetic description based on taxonomic genes such as 16SrRNA (especially when this description is performed at high phylogenetic levels such as the order) has low explanatory value, since two strains belonging to the same taxon can be or not hydrocarbonoclastic. Using short reads approaches, affiliation of sequences below the genus, or even the family is often unattainable.

The greatest differences in metabolic potential at the metagenomics level were related to signal transduction and membrane transport. These pathways were significantly more abundant in the hydrocarbon-contaminated microbial mat, whereas nucleotide metabolism and replication and repair pathways were significantly more abundant in the reference mat 
(Fig. 4). The contaminated mat was enriched with genes involved in two component systems (signal transduction, TCS) of the OmpR family (involved in copper ion efflux and manganese transport as a response of $\mathrm{Mn}$ starvation) and $\mathrm{NtrC}$ family (involved in nitrogen availability) (Table S4). The TCS are known to modify microbial physiology in response to multiple environmental signals and thus playing a role in biogeochemical cycles. Indeed, marine bacteria have varied TCS systems, and it has been proposed that lacks of TCS could be a hallmark of oligotrophy in marine systems [42]. Contaminated mat is probably enriched with TCS as an adaptive response to contamination. The overabundance of membrane transport related genes concern the ABC transporters and the type IV (T4SS) secretion systems. Recently, Xu et al. [43] described an enrichment in ABC transporters and TCS after dibutyl phthalate contamination in soils. They also observed an acceleration of nitrogen, carbon and sulfate metabolisms and suggested that $\mathrm{ABC}$ transporters and TCS were the culprits of this metabolic activation.

The T4SS are found in Gram negative bacteria, and are capable of secrete a wide variety of substances across the bacterial membranes including toxic bacterial effectors that result in cell death of rival bacteria and eukaryote [44]. T4SS is ancestrally related to bacterial DNA conjugation systems, and the T4SS-mediated genetic horizontal transfer is considered as a major contributor to bacterial genomic mobility [45]. Altogether, enrichment of ABC transporters and T4SS appears as a mechanism to control the community structure and the metabolic potential in the contaminated microbial mat.

Although less pronounced, xenobiotic biodegradation and metabolism pathways were significantly more abundant in the contaminated mat than in the reference mat. At the metatranscriptomic level, no differences in xenobiotic biodegradation and metabolism nor in the others level1 KEGG metabolic pathways were observed between the two mats (pvalue $>0.05$ or difference in mean proportions $<0.05 \%)$. 
To further characterize the hydrocarbon degradation potential of the mats, genes involved in hydrocarbon molecule activation were retrieved from the whole dataset (Fig. 5a, Table S5). These genes are specifically associated with hydrocarbon degradation, whereas those involved in intermediate reactions can be shared with other metabolic pathways (http://www.genome.jp/kegg/pathway.html). The gene encoding alkane 1-monooxygenase (alkB) (the single representative of genes involved in the fatty acid degradation pathway, Table S5), which is responsible for alkane activation, was more abundant (Wilcoxon test, pvalue $=0.03125)$ than the genes involved in degradation of aromatic compounds (Fig. 5a), as observed after the Deepwater Horizon oil spill [16]. The relative abundance and taxonomic identification of alkB were similar between the contaminated and reference mats (Fig. 5a and S1). Although the alkB gene has been widely used to investigate alkane degradation [46-49] and as a marker of petroleum degradation potential [16], its direct relationship with petroleum hydrocarbon degradation is questionable, especially in chronically contaminated environments [14]. In fact, alkB is involved in the degradation of alkanes of both biogenic and petrogenic origin. Biogenic alkanes are the consequence of organic matter degradation and are ubiquitous in nature [50]. As for alkB, the relative abundance of all the genes involved in the degradation of aromatic hydrocarbons was similar in both mats (Fig. 5a).

Analysis at the metatranscriptomic level revealed significant higher expression of genes involved in PAH activation in the contaminated mat (Fig. 5b). However, the expression of all the genes involved in $\mathrm{HC}$ activation in the contaminated mats decreased over time (Fig. 6a). Interestingly, this decrease was concomitant with changes in hydrocarbon composition during the sampling exercises (Fig. 6b). Short-chain alkanes $\left(<\mathrm{C}_{28}\right)$, medium-weight PAHs, and heavy PAHs dominated the hydrocarbons in the first, second, and last exercises, respectively. The contaminated mat was therefore enriched in recalcitrant molecules in the last exercise [20], reaching a composition similar to that previously observed at this site [8]. 
Overall, these results (chemical modification and a decrease in the expression rates of hydrocarbon activation-involved genes) suggest a progressive degradation of the more easily degradable hydrocarbons released by the overflow spill in September 2009.

A decrease in relative abundances was evident for fatty acid degradation activation genes, namely alkB (Fig. 7a). The taxonomic affiliations of the alkB transcripts suggest Alteromonadales-related bacteria as the main alkane degraders in the first sampling exercise, consistent with a previous study of the Berre lagoon in which Marinobacter aquaeolei was the dominant alkB phylotype [14]. The relative abundance of alkB transcripts decreased over time in parallel with the decrease in lower-molecular-weight alkanes. Transcripts involved in PAH degradation also decreased, albeit to a lesser extent, with Oceanospirillales-related bacteria as the main actors (Fig. $7 b$ ).

\section{Conclusion}

Both mats displayed a typical structure and functioning, with dominance of Cyanobacteria and sulphur cycle related microorganisms.. Genes involved in environmental information processing were overabundant in the contaminated mat compared to the reference one. However, xenobiotic degradation metabolisms represented a minor part of the metagenome and metatranscriptome, and no overabundance of hydrocarbonoclastic bacteria was observed in the contaminated mat. The expression levels of genes associated with hydrocarbon degradation pathways varied between the mats and among sampling exercises. In the contaminated mat, the expression of genes responsible for hydrocarbon activation was related to hydrocarbon composition, suggesting degradation of easily degradable molecules. The studied mat appeared robust enough to cope with hydrocarbon contamination but its seasonal behaviour was affected.

\section{Acknowledgement}


329 proofreading service. This work was supported by the French National Research Agency

330 [ANR FUNHYMAT ANR11 BSV7 014 01].

331

332 


\section{References}

1. Allen MA, Goh F, Burns BP, Neilan BA (2009) Bacterial, archaeal and eukaryotic diversity of smooth and pustular microbial mat communities in the hypersaline lagoon of Shark Bay. Geobiology 7:82-96. https://doi.org/10.1111/j.1472-4669.2008.00187.x

2. van Gemerden H (1993) Microbial mats: a joint venture. Mar Geol 113:3-25

3. Vincent WF (2002) Cyanobacterial Dominance in the Polar Regions. In: Whitton BA, Potts M (eds) The Ecology of Cyanobacteria. Springer Netherlands, pp 321-340

4. Dillon JG, Miller S, Bebout B, et al (2009) Spatial and temporal variability in a stratified hypersaline microbial mat community. FEMS Microbiol Ecol 68:46-58. https://doi.org/10.1111/j.1574-6941.2009.00647.x

5. Harris JK, Caporaso JG, Walker JJ, et al (2013) Phylogenetic stratigraphy in the Guerrero Negro hypersaline microbial mat. ISME J 7:50-60. https://doi.org/10.1038/ismej.2012.79

6. Schneider D, Arp G, Reimer A, et al (2013) Phylogenetic Analysis of a MicrobialiteForming Microbial Mat from a Hypersaline Lake of the Kiritimati Atoll, Central Pacific. PLoS ONE 8:e66662. https://doi.org/10.1371/journal.pone.0066662

7. Barth HJ (2003) The influence of cyanobacteria on oil polluted intertidal soils at the Saudi Arabian Gulf shores. Mar Pollut Bull 46:1245-1252. https://doi.org/10.1016/S0025-326X(03)00374-6

8. Paissé S, Coulon F, Goñi-Urriza M, et al (2008) Structure of bacterial communities along a hydrocarbon contamination gradient in a coastal sediment. FEMS Microbiol Ecol 66:295-305. https://doi.org/10.1111/j.1574-6941.2008.00589.x

9. Bordenave S, Goñi-Urriza MS, Caumette P, Duran R (2007) Effects of Heavy Fuel Oil on the Bacterial Community Structure of a Pristine Microbial Mat. Appl Environ Microbiol 73:6089-6097. https://doi.org/10.1128/AEM.01352-07

10. Paissé S, Goñi-Urriza M, Stadler T, et al (2012) Ring-hydroxylating dioxygenase (RHD) expression in a microbial community during the early response to oil pollution. FEMS Microbiol Ecol 80:77-86. https://doi.org/10.1111/j.1574-6941.2011.01270.x

11. Abed RMM, Safi NMD, Köster J, et al (2002) Microbial Diversity of a Heavily Polluted Microbial Mat and Its Community Changes following Degradation of Petroleum Compounds. Appl Environ Microbiol 68:1674-1683. https://doi.org/10.1128/AEM.68.4.1674-1683.2002

12. Paisse S, Goni-Urriza M, Coulon F, Duran R (2010) How a Bacterial Community Originating from a Contaminated Coastal Sediment Responds to an Oil Input. Microb Ecol 60:394-405. https://doi.org/10.1007/s00248-010-9721-7

13. Abed RMM, Al-Kharusi S, Prigent S, Headley T (2014) Diversity, Distribution and Hydrocarbon Biodegradation Capabilities of Microbial Communities in Oil- 
Contaminated Cyanobacterial Mats from a Constructed Wetland. PLoS ONE 9:e114570. https://doi.org/10.1371/journal.pone.0114570

14. Paisse S, Duran R, Coulon F, Goñi-Urriza M (2011) Are alkane hydroxylase genes (alkB) relevant to assess petroleum bioremediation processes in chronically polluted coastal sediments? Appl Microbiol Biotechnol 92:835-844. https://doi.org/10.1007/s00253-011-3381-5

15. Lu Z, Deng Y, Van Nostrand JD, et al (2012) Microbial gene functions enriched in the Deepwater Horizon deep-sea oil plume. ISME J 6:451-460. https://doi.org/10.1038/ismej.2011.91

16. Mason OU, Hazen TC, Borglin S, et al (2012) Metagenome, metatranscriptome and single-cell sequencing reveal microbial response to Deepwater Horizon oil spill. Isme J 6:1715-1727. https://doi.org/10.1038/ismej.2012.59

17. Rivers AR, Sharma S, Tringe SG, et al (2013) Transcriptional response of bathypelagic marine bacterioplankton to the Deepwater Horizon oil spill. ISME J 7:2315-2329. https://doi.org/10.1038/ismej.2013.129

18. de Menezes A, Clipson N, Doyle E (2012) Comparative metatranscriptomics reveals widespread community responses during phenanthrene degradation in soil. Environ Microbiol 14:2577-2588. https://doi.org/10.1111/j.1462-2920.2012.02781.x

19. Mason OU, Scott NM, Gonzalez A, et al (2014) Metagenomics reveals sediment microbial community response to Deepwater Horizon oil spill. ISME J 8:1464-1475. https://doi.org/10.1038/ismej.2013.254

20. Aubé J, Senin P, Pringault O, et al (2016) The impact of long-term hydrocarbon exposure on the structure, activity, and biogeochemical functioning of microbial mats. Mar Pollut Bull 111:115-125. https://doi.org/10.1016/j.marpolbul.2016.07.023

21. Pringault $\mathrm{O}$, Aube J, Bouchez $\mathrm{O}$, et al (2015) Contrasted effects of natural complex mixtures of PAHs and metals on oxygen cycle in a microbial mat. Chemosphere 135:189-201. https://doi.org/10.1016/j.chemosphere.2015.04.037

22. Beau-Monvoisin N (2009) Déversement accidentel d'hydrocarbures, sur l'étang de Berre suite à un débordement des bassins d'orage de la Compagnie Pétrochimique de Berre (CPB). Brest : Cedre (Centre de documentation de recherche et d'expérimentations sur les pollutions accidentelles des eaux)

23. Martin M (2011) Cutadapt removes adapter sequences from high-throughput sequencing reads. EMBnet.journal 17:10-12. https://doi.org/10.14806/ej.17.1.200

24. Kanehisa M, Goto S (2000) KEGG: kyoto encyclopedia of genes and genomes. Nucleic Acids Res 28:27-30

25. Frith MC, Hamada M, Horton P (2010) Parameters for accurate genome alignment. BMC Bioinformatics 11:80. https://doi.org/10.1186/1471-2105-11-80 
26. Moriya Y, Itoh M, Okuda S, et al (2007) KAAS: an automatic genome annotation and pathway reconstruction server. Nucleic Acids Res 35:W182-185. https://doi.org/10.1093/nar/gkm321

27. Segata N, Waldron L, Ballarini A, et al (2012) Metagenomic microbial community profiling using unique clade-specific marker genes. Nat Methods 9:811-814. https://doi.org/10.1038/nmeth.2066

28. Parks DH, Tyson GW, Hugenholtz P, Beiko RG (2014) STAMP: statistical analysis of taxonomic and functional profiles. Bioinformatics 30:3123-3124. https://doi.org/10.1093/bioinformatics/btu494

29. Stewart FJ, Ulloa O, DeLong EF (2012) Microbial metatranscriptomics in a permanent marine oxygen minimum zone. Environ Microbiol 14:23-40. https://doi.org/10.1111/j.1462-2920.2010.02400.x

30. Lê S, Rennes A, Josse J, et al (2008) FactoMineR: an R package for multivariate analysis. J Stat Softw 1-18

31. Bolhuis H, Stal LJ (2011) Analysis of bacterial and archaeal diversity in coastal microbial mats using massive parallel 16S rRNA gene tag sequencing. Isme J 5:17011712. https://doi.org/10.1038/Ismej.2011.52

32. Severin I, Acinas SG, Stal LJ (2010) Diversity of nitrogen-fixing bacteria in cyanobacterial mats. FEMS Microbiol Ecol 73:514-525. https://doi.org/10.1111/j.15746941.2010.00925.x

33. Robertson CE, Spear JR, Harris JK, Pace NR (2009) Diversity and Stratification of Archaea in a Hypersaline Microbial Mat. Appl Environ Microbiol 75:1801-1810. https://doi.org/10.1128/AEM.01811-08

34. Mobberley JM, Khodadad CLM, Visscher PT, et al (2015) Inner workings of thrombolites: spatial gradients of metabolic activity as revealed by metatranscriptome profiling. Sci Rep 5:12601. https://doi.org/10.1038/srep12601

35. Wieland A, Zopfi J, Benthien M, Kühl M (2005) Biogeochemistry of an iron-rich hypersaline microbial mat (Camargue, France). Microb Ecol 49:34-49. https://doi.org/10.1007/s00248-003-2033-4

36. Pinckney J, Paerl HW, Fitzpatrick M (1996) Impacts of seasonality and nutrients on microbial mat community structure and function. Oceanogr Lit Rev 3:283

37. Lamendella R, Strutt S, Borglin SE, et al (2014) Assessment of the Deepwater Horizon oil spill impact on Gulf coast microbial communities. Aquat Microbiol 5:130. https://doi.org/10.3389/fmicb.2014.00130

38. Atlas RM, Stoeckel DM, Faith SA, et al (2015) Oil Biodegradation and Oil-Degrading Microbial Populations in Marsh Sediments Impacted by Oil from the Deepwater Horizon Well Blowout. Environ Sci Technol 49:8356-8366. https://doi.org/10.1021/acs.est.5b00413 
39. Nogales B, Lanfranconi MP, Piña-Villalonga JM, Bosch R (2011) Anthropogenic perturbations in marine microbial communities. FEMS Microbiol Rev 35:275-298. https://doi.org/10.1111/j.1574-6976.2010.00248.x

40. Cappello S, Caruso G, Zampino D, et al (2007) Microbial community dynamics during assays of harbour oil spill bioremediation: a microscale simulation study. J Appl Microbiol 102:184-194. https://doi.org/10.1111/j.1365-2672.2006.03071.x

41. Kostka JE, Prakash O, Overholt WA, et al (2011) Hydrocarbon-Degrading Bacteria and the Bacterial Community Response in Gulf of Mexico Beach Sands Impacted by the Deepwater Horizon Oil Spill. Appl Environ Microbiol 77:7962. https://doi.org/10.1128/AEM.05402-11

42. Held NA, McIlvin MR, Moran DM, et al (2019) Unique Patterns and Biogeochemical Relevance of Two-Component Sensing in Marine Bacteria. mSystems 4:e00317-18. https://doi.org/10.1128/mSystems.00317-18

43. Xu W, You Y, Wang Z, et al (2018) Dibutyl phthalate alters the metabolic pathways of microbes in black soils. Sci Rep 8:2605. https://doi.org/10.1038/s41598-018-21030-8

44. Green ER, Mecsas J (2016) Bacterial Secretion Systems: An Overview. Microbiol Spectr 4:. https://doi.org/10.1128/microbiolspec.VMBF-0012-2015

45. Waksman G (2019) From conjugation to T4S systems in Gram-negative bacteria: a mechanistic biology perspective. EMBO Rep 20:e47012. https://doi.org/10.15252/embr.201847012

46. Vomberg A, Klinner U (2000) Distribution of alkB genes within n-alkane-degrading bacteria. J Appl Microbiol 89:339-348. https://doi.org/10.1046/j.13652672.2000.01121.x

47. Van Beilen JB, Li Z, Duetz WA, et al (2003) Diversity of Alkane Hydroxylase Systems in the Environment. Oil Gas Sci Technol 58:427-440.

https://doi.org/10.2516/ogst:2003026

48. Beilen JB van, Funhoff EG (2007) Alkane hydroxylases involved in microbial alkane degradation. Appl Microbiol Biotechnol 74:13-21. https://doi.org/10.1007/s00253-0060748-0

49. Smith CB, Tolar BB, Hollibaugh JT, King GM (2013) Alkane hydroxylase gene (alkB) phylotype composition and diversity in northern Gulf of Mexico bacterioplankton. Front Microbiol 4:. https://doi.org/10.3389/fmicb.2013.00370

50. Widdel F, Rabus R (2001) Anaerobic biodegradation of saturated and aromatic hydrocarbons. Curr Opin Biotechnol 12:259-276. https://doi.org/10.1016/S09581669(00)00209-3 
Figure captions:

483

484

485

486

487

488

489

490

491

492

493

494

495

496

497

498

499

500

501

502

503

504

505

Fig. 1 Metagenome (DNA based) and metatranscriptome (mRNA based) taxonomic structure at the class level based on the affiliation of sequences. The figure shows the fraction of reads that hits with the KEGG database. Data represent the mean of triplicates. EDB1: highly contaminated mat; SL: reference mat. The dashed lines separate from the bottom to the top: Cyanobacteria, Proteobacteria and Bacteroidetes

Fig. 2 Metabolic structure of the metagenome and metatranscriptome of both microbial mats based on $\mathrm{KO}$ assignation and pathways of sequences (relative abundance). Data represent the mean of triplicates. EDB1: highly contaminated mat; SL: reference mat. The dashed lines separate the energy metabolic pathways.

Fig. 3 LEfSe analysis of the microorganisms differentially abundant (metagenomes; a) and active (metatranscriptomes; b) in contaminated (EDB1, red) and reference (SL, green) microbial mats. Roots of cladograms stand for the domain, and concentric circles represent the following taxonomic levels until the order. Only class with p-value below 0.05 are shown.

Fig. 4 Comparison (White's non-parametric t-test in STAMP) of functional gene annotations of metagenomes using KEGG pathways (level 1). Plots compare the hydrocarbon contaminated mat (EDB1) in black to the reference (SL) in white. Only pathways with p-value below 0.05 , with difference in mean proportions above $0.05 \%$ are shown.

Fig. 5 Extended error plots comparison of the hydrocarbon degradation-related genes or transcripts in the metagenome (a) and metatranscriptome (b) data. Only the genes involved in the activation of the hydrocarbon molecules were considered (Table S5). The plot compares the hydrocarbon contaminated mat (EDB1) in black to the reference (SL) in white. 
507 Fig. 6 Expression level of genes involved in hydrocarbon degradation (Table S5) in mats (a); 508 in black, contaminated site (EDB1) in white, reference (SL) mat. Principal Component biplot 509 (PCA) based on hydrocarbon contents in EDB1 (b): A, Anthracene; ANA, Acenaphtene; ANY, 510 Acenaphtylene; BA, Benzo(a)anthracene; BAP, Benzo(a)pyrene; DBA, 511 Dibenz(a,h)anthracene; F, Fluorene; FL, Fluoranthene; IN, Indeno(1,2,3-cd)pyrene; P, 512 Phenanthrene; PY, Pyrene. C11-C16, sum of alkanes from C11 to C16; C17-C22, sum of 513 alkanes from $\mathrm{C} 17$ to $\mathrm{C} 23$; C24-C28, sum of alkanes from $\mathrm{C} 24$ to $\mathrm{C} 28$. The parameters with a $514 \cos 2$ below 0.5 are not shown (Benzo(g,h,i)perylene; Chrysene; Naphtalene; 515 Benzo(b+k)fluoranthene).

Fig. 7 Relative abundance (\%) and affiliation of transcripts involved in the activation of fatty 518 acids (alkB transcripts in our study, exclusively) (a) and polycyclic aromatic hydrocarbon (b) 519 degradation pathways. Figure shows the fraction of reads that hits with the KEGG database. Data represent the mean of the triplicates. 